\title{
Infrared Temperature Measurement System applied to the Measurement of Thermal Diffusivity
}

\author{
by C. J. M. Vicente, R. A. N. Ferreira, O. Miranda, P. A. Grossi, F. L. Migliorini, D. M. Camarano \\ Centro de Desenvolvimento da Tecnologia Nuclear, Comissão Nacional de Energia Nuclear, \\ Av. Presidente Antônio Carlos 6627 Campus da UFMG - Pampulha, Caixa Postal 941, \\ CEP 31.161-970, Belo Horizonte, Minas Gerais, Brazil, vicentecjm@gmail.com, ranf@cdtn.br, \\ odairm@cdtn.br, pabloag@cdtn.br,flmigliorini@gmail.com,dmc@cdtn.br
}

\begin{abstract}
The Laser Flash measurements for thermophysical properties determination is based on measurements of dynamics temperature transients. The dynamic effects or thermal inertia of commercial temperature measurement systems are representative and could not be ignored due to the fast dynamics of the measured thermal transients. This paper presents a mathematical modeling developed for the infrared temperature measurement system of an experimental system for thermal diffusivity measurements based on the Laser Flash Method. This reduced price and suitable developed system is based on commercial Dewar infrared detectors, collimation lens and a mathematical model developed on LabVIEW framework. As result, the electric signal generated by the infrared detector is converted to temperature signal and the necessary corrections between the emission surface, optical path and detector are performed by the model.
\end{abstract}

Key words: Infrared Radiation Thermometer, Laser Flash Method, Thermal Diffusivity

\section{Introduction}

The determination of thermal diffusivity by Flash Laser method [1,2] is based on the variation of temperature on the opposite side of a thin cylindrical sample result of a short pulse of energy received on its front side. The result of this increase in temperature is obtained from a thermogram and the thermal diffusivity is calculated as a function of sample thickness and the time required to reach half of the maximum rate of temperature on the opposite side. The improvement of the measurement method by developing a system to temperature measurement by infrared radiation with a response time of the order of nanoseconds and wide measurement range has become a priority to improve the quality of results for the Laboratório de Medição de Propriedades termofísicas (LMPT) of Centro de Desenvolvimento da Tecnologia Nuclear $[3,4]$ (figure 1).

This work presents an innovative procedure for measuring the temperature applied to the measurement of thermal diffusivity. The mathematical modeling of this system is shown below as well as its computational implementation.

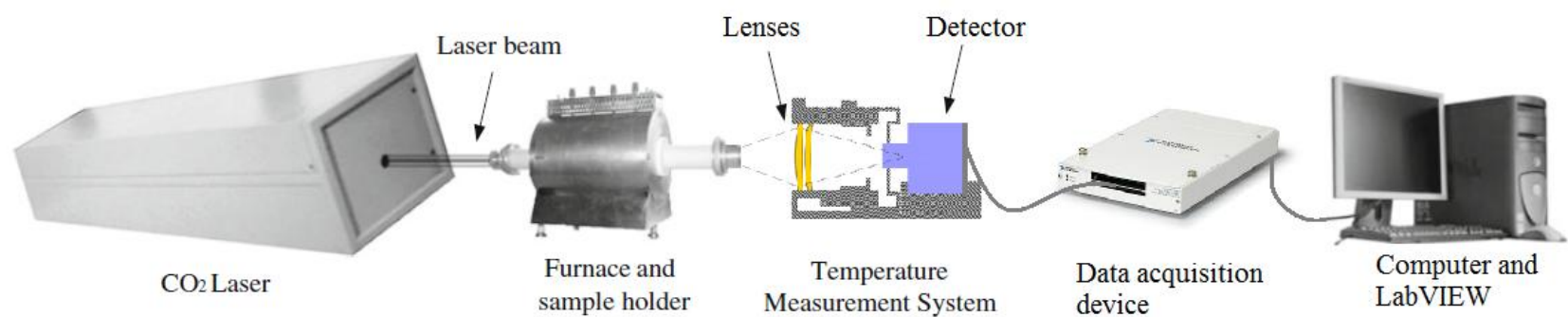

Fig. 1. Thermophysical properties measurement laboratory experimental apparatus.

\section{Mathematical model}

The temperature measurement system has been divided into two phases. The first phase is related with the project which involved the design and construction of the system. The HgCdTe detector is a photoconductive element which undergoes a change in resistance proportional to the incident infrared radiation. It is mounted in the metal dewar with $\mathrm{ZnSe}$ window and it offers optimum performance in the 8 to $12 \mu \mathrm{m}$. The second phase is related with the signal processing using LabVIEW. We used the J15D series HgCdTe detector and model PA-101 preamplifier voltage of the Teledyne Judson Technologies with the following characteristics: 
HgCdTe detector

Active area size:

Cutoff wavelength (20\%)

Peak wavelength

Peak detectivity @ 10 kHz

Responsivity @peack

Time constant

\section{PA 101 preamplifier}

Bandwith

Gain

Input impedance

Input noise

Maximum Output level (high impedande load)
$4 \mathrm{~mm}^{2}$

$>12 \mu \mathrm{m}$

$(11 \pm 1) \mu \mathrm{m}$

$\min 1 \times 10^{10} \mathrm{~cm} \mathrm{~Hz}^{1 / 2} \mathrm{~W}^{-1}$

typical $1.5 \times 1010 \mathrm{~cm} \mathrm{~Hz} \mathrm{1/1} \mathrm{W-1}$

$100 \mathrm{~V} / \mathrm{W}$

$0,5 \mu \mathrm{s}$

$1 \mathrm{st}$ stage $10 \mathrm{~Hz}$ to $1 \mathrm{MHz} 2 \mathrm{nd}$ stage $10 \mathrm{~Hz}$ to $200 \mathrm{kHz}$

1 st stage $100 x$ 2nd stage $10 x$

$10 \mathrm{k} \Omega$ through $100 \mu \mathrm{F}$ capacitor

$1,5 \mathrm{nV} \mathrm{Hz}$

$10 \vee p-p$

In this initial configuration we selected ZnSe lens, a multifunctional board for acquisition and a microcomputer for signal processing using LabVIEW. The electrical signal corresponding to the radiation emitted from a blackbody, $S_{b b}$ $\left(T_{b b}\right)$ can described by [5]:

$$
S_{b b}\left(T_{b b}\right)=g \cdot \frac{R^{*} \cdot A_{d} \cdot \tau_{0}}{4 \cdot F^{2}+1} \cdot \int_{\lambda_{1}}^{\lambda_{2}} M\left(T_{b b}, \lambda\right) \cdot s(\lambda) \cdot d \lambda .
$$

Where $g$ is the amplification of the electronic block, $R^{\star}$ is the peak detector spectral sensitivity given in $\mathrm{V} \cdot \mathrm{W}^{-1}, A_{\mathrm{d}}$ is the detector area in $\mathrm{cm}^{2}, F$ represents the ratio of focal length of the lens and diameter of the objective, $\lambda_{1}$ and $\lambda_{2}$ are the limits of the spectral band of the detector in $\mathrm{nm}, M(T, \lambda)$ is the spectral exitance at the temperature $T$ and wavelength $\lambda\left(\mathrm{W} \cdot \mathrm{m}^{-2} \cdot \mu \mathrm{m}^{-1}\right), \tau_{0}$ is the transmittance of the lens used and $s(\lambda)$ is the detector relative spectral detectivity function. The measuring signal, $S_{r}(T)$ related to the temperature of any object under measurement conditions, can be expressed by $[5,6]:$

$$
S_{r}(T)=\varepsilon \tau S_{o b j}(T)+(1-\varepsilon) \tau S_{\text {refl }}\left(T_{\text {refl }}\right)+(1-\tau) S_{\text {env }}\left(T_{\text {env }}\right)+S_{\text {opt }}\left(T_{\text {opt }}\right)+\Delta S
$$

where $S_{o b j}(T)$ is the electrical signal corresponding to the radiation emitted by the object, $\varepsilon$ is the effective emissivity of the object and $\tau$ is the effective transmissivity of the atmosphere. $S_{\text {refl }}\left(T_{\text {refl }}\right)$ is the electrical signal corresponding to the radiation reflected from the surrounding objects, $S_{\text {env }}\left(T_{e n v}\right)$ is the signal corresponding to the radiation emitted (or absorbed) by the environment between the object and the detector. $S_{\text {opt }}\left(T_{\text {opt }}\right)$ is the electrical signal corresponding to the radiation emitted by the optical components and $\Delta S$ is the residual error (eg., size of source effect, drift of detector limited digital resolution). The temperature $T_{\text {out }}$ of the object is calculated based on the value determined from the corrected signal $S_{r}(T)$ converted to temperature using the calibration data. To verify the validity, reference samples of Pure Iron and Pyroceram 9606 were used.

\section{Results}

The mathematical model developed was implemented using the LabVIEW platform and its block diagram is shown in figure 2. The detector features, optical and geometrical properties, environmental influences and others parameters considered on the Eq. 1 and 2 are used as mathematical model settings as shown in figure 3.

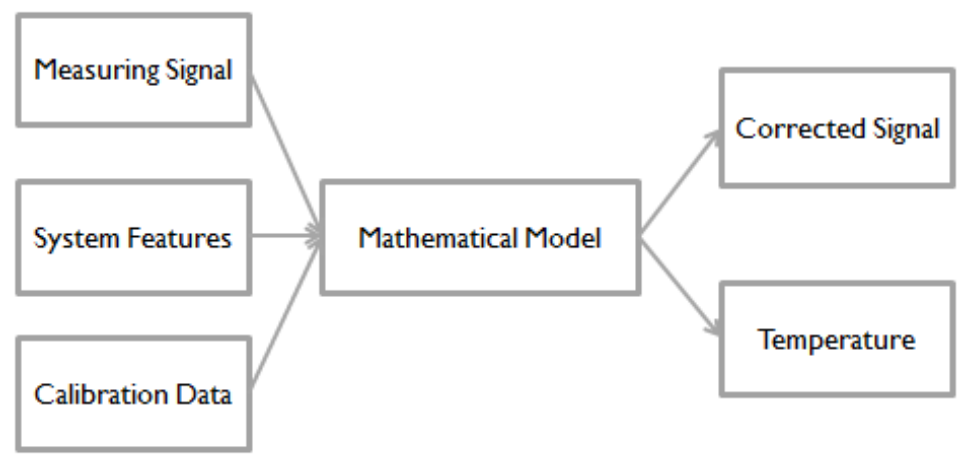

Fig. 2. Block diagram of the application. 


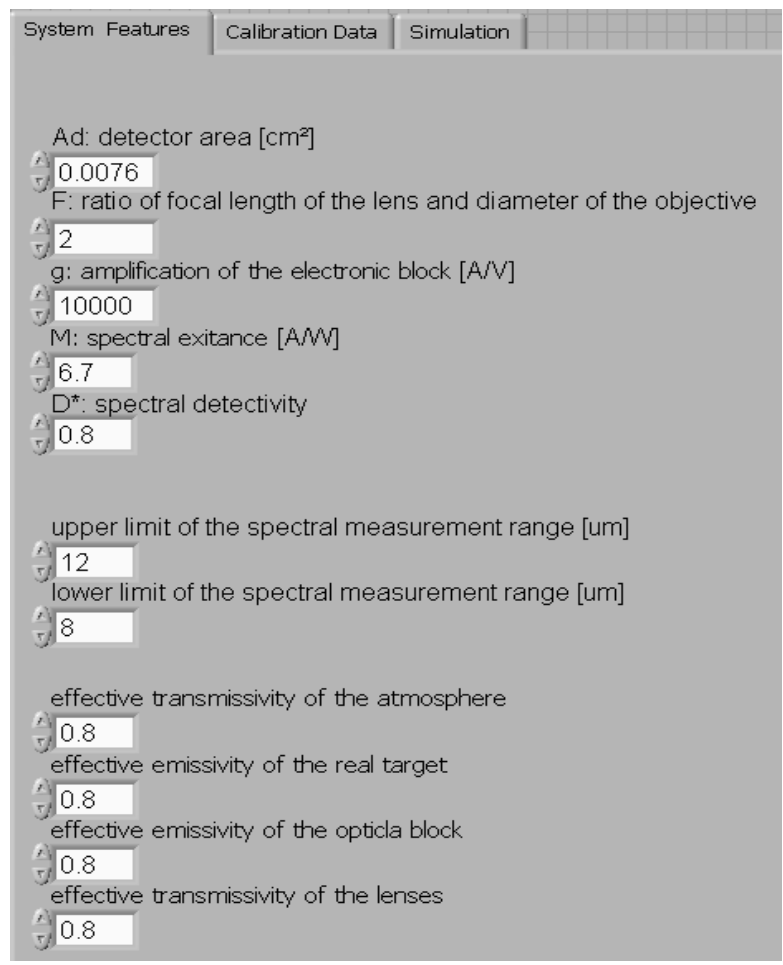

Fig. 3. Mathematical model settings

The measuring signal $\left(S_{o b j}\right)$ is acquired and corrections are performed according to the equation (2) to obtain the electrical signal corresponding to the radiation emitted by the object $\left(S_{r}\right)$. The figure 4 shows those signals considering a typical Laser Flash measurement.
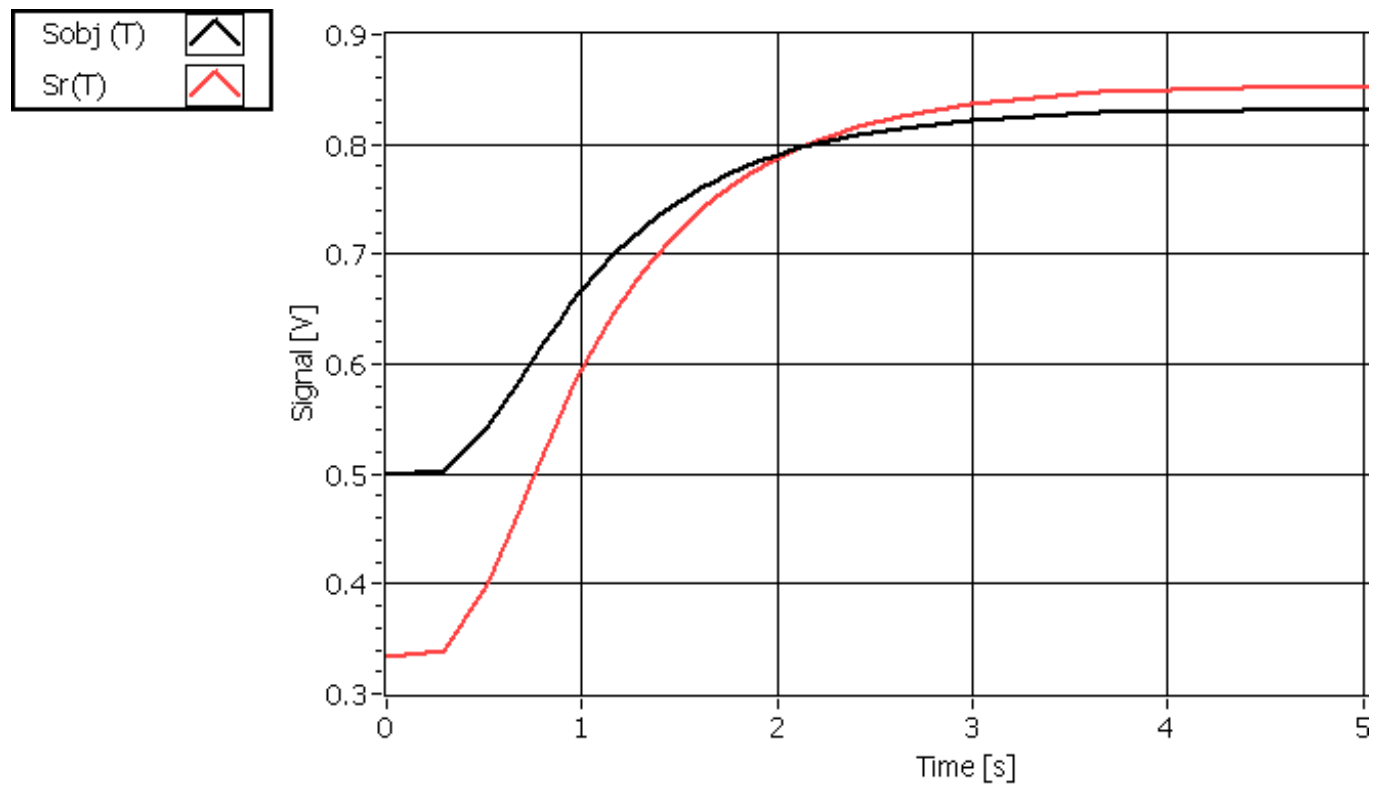

Fig. 4. Typical signals obtained from Laser Flash measurements: $S_{o b j}$ and $\left(S_{r}\right)$.

In order to obtain the temperature values of the object under measurement a calibration curve must be obtained based on a calibration process using an ideal blackbody. The output temperature $T_{\text {out }}$ is calculated on the basis of the determined value of the corrected signal $S_{r}$ and calibration curve as shown in figure 5 . 


\section{Object Temperature $\left[{ }^{\circ} \mathrm{C}\right]$}

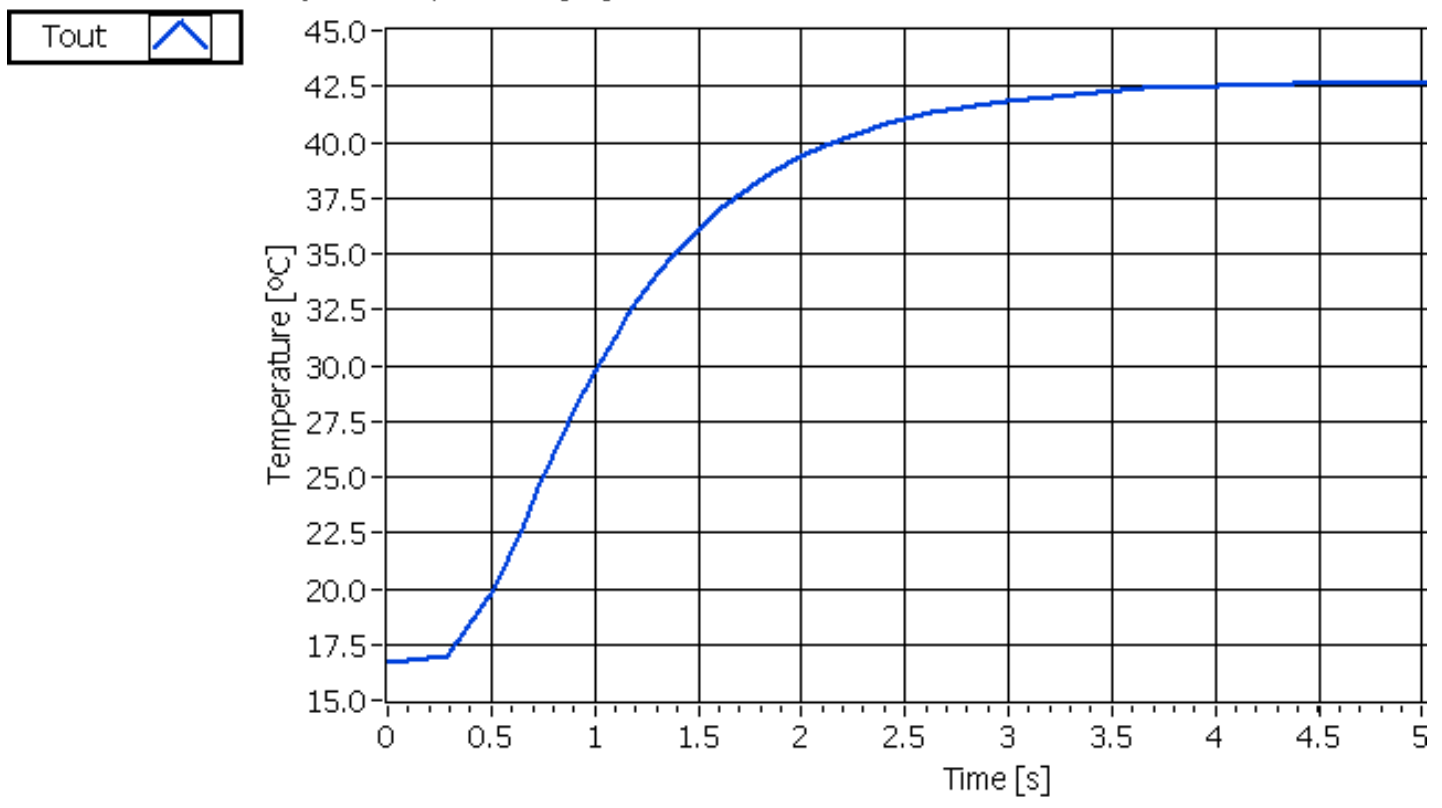

Fig. 5. Typical temperature signal obtained from Laser Flash measurements.

\section{Conclusions}

In this paper we presented a new system for measuring temperature with low response time coupled to the system for determination of thermal diffusivity using the flash method. The mathematical model was developed and implemented in LabVIEW platform for signal processing, correction and conversion of electrical signal corrected for temperature. The results show great potential for use in imaging systems used in thermal imagers, relatively low cost and adequate accuracy depending on the characteristics required for specific measurement systems with low thermal inertia and wide measurement range.

This work has been supported by the Fundação de Amparo a Pesquisa de Minas Gerais - FAPEMIG.

\section{REFERENCES}

1. Parker, W. J.; Jenkins, R. J.; Butler, C. P., Abbott, G. L., "Flash method of determining thermal diffusivity, heat capacity and thermal conductivity", Journal of Applied Physics, 32, pp.1679-1684 (1961).

2. ASTM-E-1461-07, "Standard test method for thermal diffusivity of solids by the flash method", Annual book of ASTM standards, 14.02, pp.1-11, (2007).

3. Camarano, D. M. ; F.L. Migliorini ; E.H.C. Silva ; GROSSI, P. A. ; Ferraz, W. B ; Paula, J. B. . Thermophysical Properties of Uranium-Based Niobium and Zirconium Alloys from $23 \mathrm{C}$ to $175 \mathrm{C}$. International Journal of Thermophysics, v. 31, pp. 1842-1848 (2010).

4. Grossi, P. A. Metodologia para Avaliação de Incerteza na Medição de Propriedades Termofísicas pelo Método Flash Laser: Método de Monte Carlo aplicado a Modelos Dinâmicos de Saída Multivariável. Tese (Doutorado em Engenharia Mecânica), Escola de Engenharia, Universidade Federal de Minas Gerais, UFMG. v. 1. 180 p. (2008)

5. Chrzanowski, K., Non-Contact Thermometry - Measurement Errors, Research \& Development Treatises, vol. 7, Polish Capter of SPIE, Warsaw, 2001.

6. Vendt, R.; Juurma, M.; Jaanson, P.; Vabson, V.; Kübarsepp, T.; Noorma, M., "Effects of Environmental Conditions on the Performance of Thermal Imagers", Int. J. Thermophys, 32, pp. 247-257 (2011). 